OPEN ACCESS

Edited by:

Yok Lam Kwong,

The University of Hong Kong,

Hong Kong

Reviewed by:

Albrecht Reichle,

University Medical Center

Regensburg, Germany

Xing Fan,

National Institutes of Health (NIH),

United States

*Correspondence:

Honghu Zhu

zhuhhdoc@163.com

Specialty section:

This article was submitted to Hematologic Malignancies,

a section of the journal

Frontiers in Oncology

Received: 21 August 2020

Accepted: 17 December 2020

Published: 05 February 2021

Citation:

Lou Y, Ma Y, Jin J and Zhu H (2021)

Oral Realgar-Indigo Naturalis Formula

Plus Retinoic Acid for Acute

Promyelocytic Leukemia.

Front. Oncol. 10:597601.

doi: 10.3389/fonc.2020.597601

\section{Oral Realgar-Indigo Naturalis Formula Plus Retinoic Acid for Acute Promyelocytic Leukemia}

\author{
Yinjun Lou, Yafang Ma, Jie Jin and Honghu Zhu* \\ Department of Hematology, Leukemia Center, The First Affiliated Hospital of Zhejiang University, College of Medicine, Key \\ Laboratory of Hematopoietic Malignancies in Zhejiang Province, Hangzhou, China
}

Treatment paradigm of acute promyelocytic leukemia (APL) is by no mean the most remarkable story of cancer therapy. Recently, the advent of oral arsenic formulations (oralarsenic trioxide and Realgar-Indigo Naturalis formula (RIF)) based regimens may provide a therapeutic advance by curing APL with two oral agents. Indeed, the oral RIF plus alltrans-retinoic acid (ATRA) without chemotherapy display highly efficacy in patients with APL. The safety profile of RIF plus ATRA make possible to treat APL patients in a homebased manner during postremission therapy. To our knowledge, RIF was the first commercially available oral arsenic agent approved in China. The RIF plus ATRA regimens are becoming a preferred frontline care for APL in China. In this review, we will discuss the history, current evidences and challengers of RIF-based strategies in APL. More and more APL patients may enjoy a cure with a normal quality-of-life after induction in the near future.

Keywords: realgar-indigo naturalis formula, all-trans retinoic acid, PML-RARA, arsenic trioxide, chemotherapy-free

\section{INTRODUCTION}

Acute promyelocytic leukemia (APL) was first described in 1923 by Swiss hematologist Dr. Albert Alder (1). In the 1950s, LK Hillestad and J Bernard further described a case series and recognized as a clinical entity of APL by its unique morphologic characteristics with prominent granules and hemorrhagic diathesis features $(2,3)$. Importantly, the initial breakthrough was the uncover of the unique chromosomal aberration $\mathrm{t}(15,17)$ (q22;q12) in APL by Dr. J Rowley in 1970s (4). However, it was not until 1990, the landmark molecular fusion of the promyelocytic leukemia (PML) and retinoic acid receptor alpha (RARA) gene was identified (5). Given the central role of PML-RARA in the leukemogenesis of APL, the chimeric oncoprotein was considered an idea molecular target for antileukemic therapy.

Surprising, the targeted therapy to PML-RARA for APL was developed by an empirical-based way. As early as in 1985, all-trans-retinoic acid (ATRA) was first administrated in the induction treatment of APL by Dr. Wang ZY and his team from Shanghai Institute of Hematology (6). The combination of ATRA and anthracycline-based protocol significantly improved the long-term outcome of APL (7). In 1970s, another miracle agent, intravenous arsenic trioxide (ATO) was observed preliminary evidence of efficacy in APL patients by Dr. Zhang TD et al. from Harbin Medical University (8). Subsequent studies by Dr. Chen Z et al. confirmed the high efficacy and 
safety of intravenous ATO for APL, initially in relapsed patients and then for newly diagnosed patients (9-11).

Along with the clinical progress, basic investigators have revealed that both ATO and ATRA directly targeted the PMLRARA, which trigger the degradation of the PML-RARA fusion oncoprotein (12). Additionally promising, ATO was found to target PML protein directly (13). The targeted therapy model assumed to eradicate the APL-initiating cells and ultimately reduce the need for chemotherapy (14). In line with this preclinical model, the followup trials demonstrated that the ATO plus ATRA targeted approach could definitively cure APL (14). Thus, ATRA and arsenic were defined as a "magic bullet" for APL.

\section{ORAL REALGAR-INDIGO NATURALIS FORMULA DEVELOPMENT AND PILOT STUDIES}

Realgar (contains approximately $90 \% \mathrm{As}_{4} \mathrm{~S}_{4}$ ), an oral form of arsenic compound, is an agent originally used as traditional Chinese medicine. As early as in 1980s, Dr. Huang SL et al. initially developed a Realgar-Indigo Naturalis Formula (RIF) for APL. RIF (250 mg per pill) was the combination of four natural products: Realgar (30 mg per pill), Indigo naturalis (125 mg per pill), Radix salviae miltiorrhizae (50mg per pill) and Radix pseudostellariae (45 $\mathrm{mg}$ per pill).

Similar to $\mathrm{ATO}, \mathrm{As}_{4} \mathrm{~S}_{4}$ induces the ubiquitination and degradation of PML-RARA, and relocalization of PML protein in primary APL cells was observed. Interestingly, the four components of RIF could make synergistic effect and strengthen the antileukemia effect (15). Clinical data accumulated over the last decades of RIF-based therapy in APL. Here, Table 1 summarized the main publication data of RIF-based treatment for APL.

In 1995, Dr. Huang SL et al. undertook a pilot study of APL patients treated by oral RIF based induction in six Chinese centers from 1988 to 1993 (16). Forty-three patients were newly diagnosed APL and 17 were relapsed APL. Patients received RIF till completely remission (CR) or 60 days. The dose was started with 15 pills daily and gradually ramp-up to 30 pills daily in a week. Glucocorticoid or low-dose chemotherapy was allowed. The overall CR rate was $98.3 \%$. All patients have received RIF more than 30 days achieved CR. Moreover, the side effects of RIF appeared generally manageable. The frequent main side effects were epigastria discomfort, abdominal distention, mild diarrhea, skin rash, and liver enzyme increase. This is the first study reported the efficacy and safety of RIF-based therapy in APL. However, the postremission therapy was not clearly defined and long-term outcomes were not reported.

Subsequently, a team led by Dr. Lu DP from Peking University, first isolated highly purified crystalline $\mathrm{As}_{4} \mathrm{~S}_{4}$ from natural Realgar. A total of 129 APL patients were enrolled during 1994-2000 (17). During induction, $\mathrm{As}_{4} \mathrm{~S}_{4}$ was orally administered at a dosage of $50 \mathrm{mg} / \mathrm{kg} /$ day (four times daily) until CR. After CR1, patients received $\mathrm{As}_{4} \mathrm{~S}_{4}$ single agent for postremission therapy. The results were quite encouraging. In

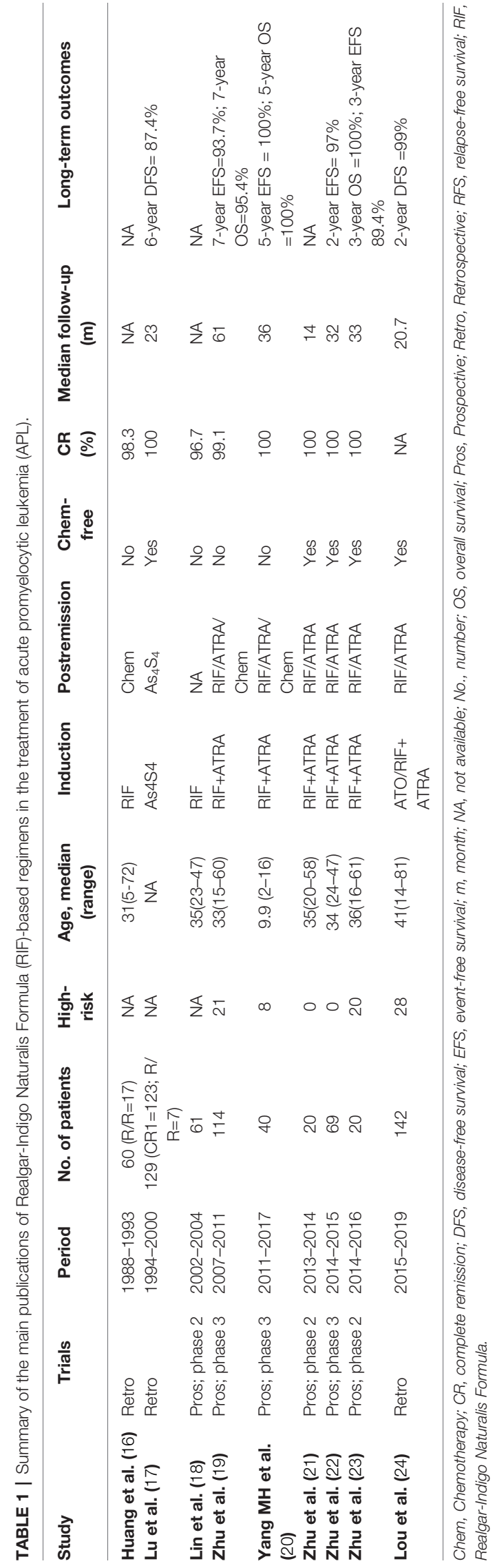


the newly diagnosed group $(n=15)$, the 3-year disease-free survival (DFS) rates was $76.6 \%$. In the CR1 group $(n=99)$, the 6-year DFS rates were $87.4 \%$. The data suggested that oral $\mathrm{As}_{4} \mathrm{~S}_{4}$ single agent could cure more than $70 \%$ of APL patients. This seems consistent with APL patients using single intravenous ATO regimen.

In terms of toxicity, $\mathrm{As}_{4} \mathrm{~S}_{4}$ was usually well tolerated, such as asymptomatic QTc prolongation (33\%), transient elevation in liver enzyme levels (10.5\%), mild nausea (3.2\%), skin itching (3.2\%). No myelosuppression occurred during postremission therapy. Pharmacokinetic and pharmacodynamic analysis of $\mathrm{As}_{4} \mathrm{~S}_{4}$ was performed in seven patients. Both blood and urinary arsenic levels eliminated after discontinuation of $\mathrm{As}_{4} \mathrm{~S}_{4}$.

\section{RANDOMIZED TRIALS: ORAL REALGAR- INDIGO NATURALIS FORMULA VERSUS ALL-TRANS-RETINOIC ACID}

To further evaluate the effective and side effects of oral RIF in APL, the Chinese APL Cooperative Group conducted a prospective Phase II trial to compare the efficacy and safety of RIF versus ATRA based induction therapy in patients with newly diagnosed APL (18). During induction, patients received RIF (dose ramp up from 15 pills/day to 30 pills/day in 10 days), or ATRA at $25 \mathrm{mg} / \mathrm{m}^{2} /$ day (in two divided doses). Low intensive chemotherapy was used for cytoreduction. By intention-to- treat (ITT) analysis, the CR rate was $80.8 \%$ in RIF group versus $75.7 \%$ in the ATRA group $(\mathrm{P}>0.05)$. The trial suggested that RIF was an alternative choice of APL. The main limitation of the study was not available of long-term outcomes.

\section{RANDOMIZED TRIALS: ORAL REALGAR- INDIGO NATURALIS FORMULA PLUS ALL-TRANS-RETINOIC ACID VERSUS INTRAVENOUS ARSENIC TRIOXIDE PLUS ALL-TRANS-RETINOIC ACID}

Based on the phase II trial, the Chinese APL Cooperative Group further conducted a phase III multicenter, randomized, prospective study between 2007 and 2011 (ChiCTR-TRC-12002151), which compared RIF plus ATRA versus ATO plus ATRA based regiment in front-line therapy of all-risk APL (19). During induction, patients were given oral RIF (60 mg/kg/day, orally in three divided doses) or ATO $(0.16 \mathrm{mg} / \mathrm{kg})$ combined with ATRA $\left(25 \mathrm{mg} / \mathrm{m}^{2} /\right.$ day, orally in two divided doses). On achieving CR1, patients received three cycles of chemotherapy and maintenance with sequential RIF or ATO plus ATRA for 2 years. The study was a noninferiority design and the primary end point was DFS.

A total of 242 patients were enrolled at seven centers. The 2year DFS was $98.1 \%$ in the RIF group versus $95.5 \%$ in the ATO group and confirmed the noninferiority $(\mathrm{P}<0.001)$. Similar hematologic and non-hematologic adverse events were reported. Moreover, pharmacodynamics analysis showed oral
RIF were similar to intravenous ATO. Thus, this is the first study demonstrate that an oral RIF and intravenous ATO have broadly similar efficacy and safety. In addition, the updated results revealed the estimated 7-year EFS and OS rates were similar between the RIF and ATO groups (94\% versus $89 \%, \mathrm{P}=0.37$; $95 \%$ versus. $91 \%, \mathrm{P}=0.31$, respectively) (25). The estimated 7 year EFS and OS were also similar between the high-risk and non-high-risk groups (25).

Since the oral RIF plus ATRA may be easier for pediatric patients to take, the South China Children Leukemia Group (SCCLG) conducted a randomized study to compare the efficacy, safety and the number of hospital days between RIF or $\mathrm{f}$ intravenous ATO-based therapies in pediatric APL (20). The induction and consolidation treatment contained ATO or RIF plus ATRA and low intensity chemotherapy. The RIF was given at a dose of $135 \mathrm{mg} / \mathrm{kg} /$ day ( $\ngtr 30$ pills/day). Intravenously ATO was given at a dose of $0.16 \mathrm{mg} / \mathrm{kg} /$ day ( $\ngtr 10 \mathrm{mg} /$ day). The results showed the 5-year EFS was $100 \%$ in both groups. The data suggested that oral RIF was similar efficacy and safe with intravenous ATO in pediatric APL patients, with the advantage of reducing hospital stay days.

Base on the phase II trial and the phase III trial, the therapeutic effect of RIF in APL is well established. The Chinese Food and Drug Administration approved RIF as the first-line treatment for APL. RIF was implemented into the treatment algorithm and widely used for APL in China. The optimal recommended dose of RIF was $60 \mathrm{mg} / \mathrm{kg} /$ day in adult.

\section{CHEMOTHERAPY-FREE APPROACH: ORAL REALGAR-INDIGO NATURALIS FORMULA PLUS ALL-TRANS-RETINOIC ACID}

Although the Chinese APL07 trial achieved excellent long-term outcomes in newly diagnosed APL, the three cycles of consolidation chemotherapy have been associated with myelosuppresion, risk of cardiovascular complications and the development of therapy-related myeloid neoplasms. In 2002, Estey and coworkers from M.D. Anderson Cancer Center published the results of the combined ATRA with intravenous ATO regimen without chemotherapy regimen (only plus gemtuzumab ozogamycin for high risk patients) in newly diagnosed APL (26). The trial suggested that APL patients could be cured by targeted therapy alone. In 2013, the landmark APL0406 trial demonstrated the superior efficacy, safety and quality of life for ATO-ATRA in comparison with the ATRA plus chemotherapy regimen in non-high risk APL patients $(27,28)$. Thus, the chemotherapy-free approach was moving to the frontline in APL treatment.

Based on the previous intravenous ATO and RIF data, it is logical to apply oral RIF plus ATRA chemotherapy-free in newly diagnosed APL patients. Zhu HH et al. conducted a single arm pilot study of using the oral RIF plus ATRA protocol in non-high risk patients (26). The trial enrolled 20 patients. Oral RIF was administered (60 mg/kg/day) and ATRA (25 mg/m²/day) as induction therapy. Postremission therapy schedule was RIF with 
a 4 weeks on and 4 weeks off and ATRA 2 weeks on and 2 weeks off for 7 months. All patients achieved molecular CR. No patients relapsed during the cut-off date of last follow-up (20).

Subsequently, a multicenter, non-inferiority, randomized, controlled phase 3 trial were conducted at 14 centers in China (22). The trial compared directly of oral RIF plus ATRA with intravenous ATO plus ATRA in newly diagnosed non-high-risk APL patients. The primary outcome was EFS at 2 years. A total of 109 patients were assigned to RIF-ATRA group $(n=72)$ or intravenous ATO-ATRA group $(n=37)$. The 2-year EFS was $97 \%$ versus $94 \%$. The non-inferiority outcome was also confirmed.

\section{CHEMOTHERAPY-FREE APPROACH IN HIGH-RISK ACUTE PROMYELOCYTIC LEUKEMIA}

Moreover, based on the excellent outcomes of chemotherapy-free approaches in non-high risk APL patients, this raises the question as to whether is it possible for de-escalation or even elimination of chemotherapy for the treatment of high-risk APL patients. Indeed, Zhu et al. conducted an earlier pilot single arm trial with RIF plus ATRA in 20 high-risk patients (23). Minimal cytotoxic agents were allowed during induction. The consolidation approach was RIF (60 $\mathrm{mg} / \mathrm{kg}$ daily) in a 4-week on and 4-week off regimen for four cycles and ATRA ( $25 \mathrm{mg} / \mathrm{m}^{2}$ daily) in a 2-week on and 2-week off regimen for seven cycles, which was the same postremission schedule as in non-high risk group. The data demonstrated that the 3-year estimated OS and EFS are $100 \%$ and $89.4 \%$. Although longerterm follow-up, and more patients needed, this study favored the option of chemotherapy-free regimens in high-risk APL patients.

\section{HOME-BASED MANAGEMENT OF PATIENTS DURING POSTREMISSION THERAPY}

Oral RIF and ATRA allow home treatment for APL patients during postremission therapy. The regimen may reduce the cost, hospital/ clinic visit and health care resources. It is more convenient for both patients and medical staff, especially in the season while COVID-19 became epidemic. In our experience, the safety profile of oral RIF plus ATRA was favorable during postremission therapy. The side effects are usually mild, such as associated with grade 1/2 neutropenia, gastrointestinal toxicity, and edema. Patients usually come in every 2-4 weeks for blood tests and every three months for bone marrow aspiration $(24,29)$. Majority of patients could go back to work or school with maintaining normal lives.

\section{CRITICAL ISSUES IN THE CURRENT CHEMOTHERAPY-FREE ERA}

However, despite the promising activity of oral arsenic plus ATRA chemotherapy-free approach, several challenges remain. First, early death before or during induction remain the most critical challenge in APL. Early diagnosis, intensive supportive therapy and riskadapted approach may reduce the early complications during induction. For high-risk patients, anthracyclines, or gemtuzumab ozogamycin may still be necessary to control hyperleukocytosis.

Second, although the main ingredient of RIF is $\mathrm{As}_{4} \mathrm{~S}_{4}$, RIF is a compound preparation. Usually, patients need to take about $12-$ 15 pills every day. It would be easy to take if RIF pills were modified by improving producing technology.

Our goal is to cure APL with treatments that are broadly available. RIF is not accessible outside China yet. Fortunately, trials of other oral arsenic formulations are ongoing. Kwong et al. from University of Hong Kong initially use oral-ATO in first relapse, and then in frontline of APL treatment (30). Oral-ATO may be rational to replace the intravenous ATO with emerging evidence increased. Such as, Ravandi et al. conducted a phase I clinical trials of oral-ATO (ORH-2014, NCT03048344) in patients with advanced hematologic malignancies. The Australasian Group also conducted a phase I trial (ACTRN12616001022459) using oral-ATO in APL patients.

Finally, data of chemotherapy-free approach in high-risk patients are still limited. Near future, well-designed clinical trials may possible to optimize the dose and schedule strategy of RIF plus ATRA protocol. The ongoing trials (APOLLO, NCT02688140 by the European intergroup; NCT03624270 by the University of Hong Kong, ChiCTR1900023309 in China) are evaluating the chemotherapy-free approaches in high-risk patients. The results of these trials are very expected indeed.

\section{CONCLUSIONS AND PROSPECTIVE}

More than 30 years of experience with RIF, and 10 years since the approval of RIF by the Chinese FDA, the efficacy and safety of RIF-based regiments has been well established (31). Till now, over 8,000 patients with APL have been treated with oral RIF in China. Overall, oral arsenic, a gift from nature, may representative the first oral arsenical formula applied in APL. Near one century after first describe of APL, we believe the treatment of APL is moving toward an entirely oral chemotherapy-free approach among most patients. The oral arsenic plus ATRA will ultimately make treatment safer, less financial burden, and more accessible to patients.

\section{AUTHOR CONTRIBUTIONS}

LJ, MF, JJ, and ZH conceptualized the study, wrote the manuscript, and gave the final approval of manuscript. All authors contributed to the article and approved the submitted version.

\section{FUNDING}

This work was supported by grants from the National Natural Science Foundation of China (82070151). 


\section{REFERENCES}

1. Balduini CL. 100-Year-Old Haematologica Images: Acute Promyelocytic Leukemia. Haematologica (2020) 105(2):245. doi: 10.3324/haematol.2020. 247056

2. Hillestad LK. Acute promyelocytic leukemia. Acta Med Scand (1957) 159 (3):189-94. doi: 10.1111/j.0954-6820.1957.tb00124.x

3. Bernard J, Mathe G, Boulay J, Ceoard B, Chome J. [Acute promyelocytic leukemia: a study made on 20 cases]. Schweiz Med Wochenschr (1959) 89:604-8.

4. Rowley JD, Golomb HM, Dougherty C. 15/17 translocation, a consistent chromosomal change in acute promyelocytic leukaemia. Lancet (1977) 1 (8010):549-50. doi: 10.1016/s0140-6736(77)91415-5

5. de The H, Lavau C, Marchio A, Chomienne C, Degos L, Dejean A. The PMLRAR alpha fusion mRNA generated by the $t$ () translocation in acute promyelocytic leukemia encodes a functionally altered RAR. Cell (1991) 66 (4):675-84. doi: 10.1016/0092-8674(91)90113-D

6. Huang ME, Ye YC, Chen SR, Chai JR, Lu JX, Zhoa L, et al. Use of all-trans retinoic acid in the treatment of acute promyelocytic leukemia. Blood (1988) 72(2):567-72. doi: 10.1182/blood.V72.2.567.bloodjournal722567

7. Fenaux P, Le Deley MC, Castaigne S, Archimbaud E, Chomienne C, Link H, et al. Effect of all transretinoic acid in newly diagnosed acute promyelocytic leukemia. Results of a multicenter randomized trial. European APL 91 Group. Blood (1993) 82(11):3241-9. doi: 10.1182/blood.V82.11.3241.bloodjournal82113241

8. Zhang TD, Chen GQ, Wang ZG, Wang ZY, Chen SJ, Chen Z. Arsenic trioxide, a therapeutic agent for APL. Oncogene (2001) 20(49):7146-53. doi: 10.1038/sj.onc.1204762

9. Niu C, Yan H, Yu T, Sun HP, Liu JX, Li XS, et al. Studies on treatment of acute promyelocytic leukemia with arsenic trioxide: remission induction, follow-up, and molecular monitoring in 11 newly diagnosed and 47 relapsed acute promyelocytic leukemia patients. Blood (1999) 94(10):3315-24. doi: 10.1182/ blood.V94.10.3315.422k16_3315_3324

10. Shen ZX, Chen GQ, Ni JH, Li XS, Xiong SM, Qiu QY, et al. Use of arsenic trioxide (As2O3) in the treatment of acute promyelocytic leukemia (APL): II. Clinical efficacy and pharmacokinetics in relapsed patients. Blood (1997) 89 (9):3354-60. doi: 10.1182/blood.V89.9.3354

11. Soignet SL, Maslak P, Wang ZG, Jhanwar S, Calleja E, Dardashti LJ, et al. Complete remission after treatment of acute promyelocytic leukemia with arsenic trioxide. N Engl J Med (1998) 339(19):1341-8. doi: 10.1056/ NEJM199811053391901

12. Nasr R, Guillemin MC, Ferhi O, Soilihi H, Peres L, Berthier C, et al. Eradication of acute promyelocytic leukemia-initiating cells through PMLRARA degradation. Nat Med (2008) 14(12):1333-42. doi: 10.1038/nm.1891

13. Zhang XW, Yan XJ, Zhou ZR, Yang FF, Wu ZY, Sun HB, et al. Arsenic trioxide controls the fate of the PML-RARalpha oncoprotein by directly binding PML. Science (2010) 328(5975):240-3. doi: 10.1126/science.1183424

14. de The H, Chen Z. Acute promyelocytic leukaemia: novel insights into the mechanisms of cure. Nat Rev Cancer (2010) 10(11):775-83. doi: 10.1038/nrc2943

15. Wang L, Zhou G, Liu P, Song JH, Liang Y, Yan XJ, et al. Dissection of mechanisms of Chinese medicinal formula Realgar-Indigo naturalis as an effective treatment for promyelocytic leukemia. Proc Natl Acad Sci U S A (2008) 105(12):4826-31. doi: 10.1073/pnas.0712365105

16. Shilin H, Aixia G, Yang X, Xiaobo W, Huixian L, Li F, et al. Clinical Study On The Treatment Of Acute Promyelocytic Leukemia Mainly With Composite Indigo Naturalis Tablets. Chin J Hematol (1995) 01):26-8.

17. Lu DP, Qiu JY, Jiang B, Wang Q, Liu KY, Liu YR, et al. Tetra-arsenic tetrasulfide for the treatment of acute promyelocytic leukemia: a pilot report. Blood (2002) 99(9):3136-43. doi: 10.1182/blood.V99.9.3136

18. Qian LS. Phase II clinical trial of compound Huangdai tablet in newly diagnosed acute promyelocytic leukemia. Chin J Hematol (2006) 12):801-4.
19. Zhu HH, Wu DP, Jin J, Li JY, Ma J, Wang JX, et al. Oral tetra-arsenic tetrasulfide formula versus intravenous arsenic trioxide as first-line treatment of acute promyelocytic leukemia: a multicenter randomized controlled trial. J Clin Oncol (2013) 31(33):4215-21. doi: 10.1200/JCO.2013.48.8312

20. Yang MH, Wan WQ, Luo JS, Zheng MC, Huang K, Yang LH, et al. Multicenter randomized trial of arsenic trioxide and Realgar-Indigo naturalis formula in pediatric patients with acute promyelocytic leukemia: Interim results of the SCCLG-APL clinical study. Am J Hematol (2018) 93 (12):1467-73. doi: 10.1002/ajh.25271

21. Zhu HH, Huang XJ. Oral arsenic and retinoic acid for non-high-risk acute promyelocytic leukemia. N Engl J Med (2014) 371(23):2239-41. doi: 10.1056/ NEJMc1412035

22. Zhu HH, Wu DP, Du X, Zhang X, Liu L, Ma J, et al. Oral arsenic plus retinoic acid versus intravenous arsenic plus retinoic acid for non-high-risk acute promyelocytic leukaemia: a non-inferiority, randomised phase 3 trial. Lancet Oncol (2018) 19(7):871-9. doi: 10.1016/S1470-2045(18)30295-X

23. Zhu HH, Liu YR, Jia JS, Qin YZ, Zhao XS, Lai YY. Oral arsenic and all-trans retinoic acid for high-risk acute promyelocytic leukemia. Blood (2018) 131 (26):2987-9. doi: 10.1182/blood-2018-02-834051

24. Lou Y, Tong H, Yu W, Wei J, Xu W, Mao L, et al. Efficacy and safety of early switching to an outpatient therapy model using oral arsenic plus retinoic acid based-regimen in newly diagnosed acute promyelocytic leukemia. Leukemia Res (2019) 83:106168. doi: 10.1016/j.leukres.2019.106168

25. Zhu HH, Wu DP, Jin J, Li JY, Ma J, Wang JX, et al. Long-term survival of acute promyelocytic leukaemia patients treated with arsenic and retinoic acid. $\mathrm{Br} \mathrm{J}$ Haematol (2016) 174(5):820-2. doi: 10.1111/bjh.13809

26. Estey E, Garcia-Manero G, Ferrajoli A, Faderl S, Verstovsek S, Jones D, et al. Use of all-trans retinoic acid plus arsenic trioxide as an alternative to chemotherapy in untreated acute promyelocytic leukemia. Blood (2006) 107 (9):3469-73. doi: 10.1182/blood-2005-10-4006

27. Lo-Coco F, Avvisati G, Vignetti M, Thiede C, Orlando SM, Iacobelli S, et al. Retinoic acid and arsenic trioxide for acute promyelocytic leukemia. $N$ Engl J Med (2013) 369(2):111-21. doi: 10.1056/NEJMoa1300874

28. Lou Y, Lu Y, Ye X, Wang Y, Ma Y, Fan C, et al. PML-RARA monitoring in newly diagnosed acute promyelocytic leukemia treated with an entirely oral chemotherapy-free postremission approach: A multiple institution experience. Hematol Oncol (2020) 38(4):618-21. doi: 10.1002/hon.2766

29. Cicconi L, Platzbecker U, Avvisati G, Paoloni F, Thiede C, Vignetti M, et al. Long-term results of all-trans retinoic acid and arsenic trioxide in non-highrisk acute promyelocytic leukemia: update of the APL0406 Italian-German randomized trial. Leukemia (2020) 34(3):914-8. doi: 10.1038/s41375-0190589-3

30. Gill HS, Yim R, Kumana CR, Tse E, Kwong YL. Oral arsenic trioxide, all-trans retinoic acid, and ascorbic acid maintenance after first complete remission in acute promyelocytic leukemia: Long-term results and unique prognostic indicators. Cancer (2020) 126(14):3244-54. doi: 10.1002/cncr.32937

31. Zhu HH, Hu J, Lo Coco F, Jin J. The Simpler the Better: Oral Arsenic for Acute Promyelocytic Leukemia. Blood (2019) 134(7):597-605. doi: 10.1182/ blood.2019000760

Conflict of Interest: The authors declare that the research was conducted in the absence of any commercial or financial relationships that could be construed as a potential conflict of interest.

Copyright (c) $2021 \mathrm{Lou}, \mathrm{Ma}$, Jin and Zhu. This is an open-access article distributed under the terms of the Creative Commons Attribution License (CC BY). The use, distribution or reproduction in other forums is permitted, provided the original author(s) and the copyright owner(s) are credited and that the original publication in this journal is cited, in accordance with accepted academic practice. No use, distribution or reproduction is permitted which does not comply with these terms. 